\title{
金星大気の日変化
}

名古屋大学理学部地球科学教室 浦 部 達 夫

(昭和 44 年 1 月 16 日受理)

\section{Daily Variation in the Temperature of the Cytherean Atmosphere}

\author{
Tatsuo URABE \\ Department of Earth Sciences, Faculty of Science, Nagoya University \\ (Received January 16, 1969)
}

Daily variation in the temperature of the cytherean atmosphere is discussed, based upon the radiation equilibrium condition. A coupling of two systems of day side and night side is the main interest.

According to the rotation of the planet, energy influx from the sun varies sinusoidally with time. However, variations in the radiation equilibrium temperature are not always sinusoidal, and a discontinuous jump at $350^{\circ} \mathrm{K}$ and $250^{\circ} \mathrm{K}$ is expected.

Wind of hot gas from the day side to the night side occurs continuously, and a temperature rise of $30^{\circ} \mathrm{K}$ is realized at the night side.

\section{$\S 1$. はじめに}

最近筆者は，金星の表面温度が地球のそれと非常にことなるのは何故かを，大気の組成と熱 輻射平衡との関連において論じた [SHIMAZU and URABE (1968)]. その際大気全体の組成, 温 度が均一になつているものとして扱つた。 しかし金星の 1 日は地球の 118 日に相当する長い時 間であるので，太陽に向いている側と反対側とでは温度差が大きいと考光稀ばならない。すな わち大気を昼側と夜側にわけて扱ら必要がある。

金星表面には，水が核とんどあるいは全く存在しない。この事実を水の分解，逸散といらメ カニズムで説明しようとする時, 部分的にでも高温になるところまたは時期があれば逸散に有 効であろうし, 平均化した均一温度大気モデルとは異つた効果も現われるはずである，逆に部 分的にでも低温部がある時, 原料としての水さえあれば液相 (海洋)の存在する可能性もある. 以上の理由から太陽に面した側と反対側との温度の日変化について考察する。

\section{§ 2. モ デル}

金星表面のある地点とその反対側の 地点とにそれぞれ 単位断面積をもつた大気柱を考学る 

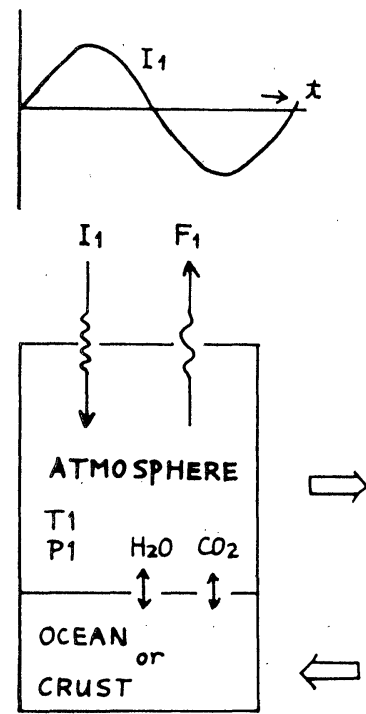
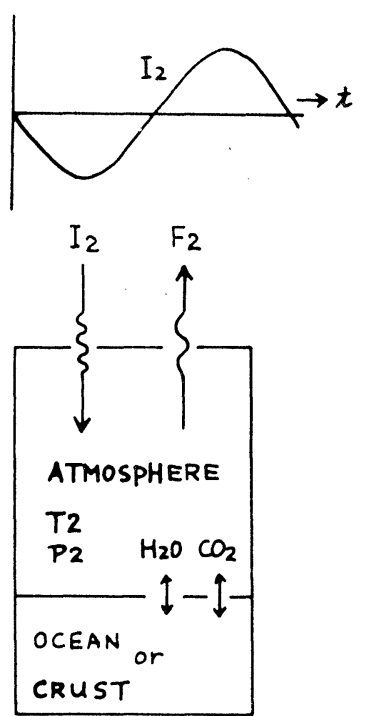

Fig. 1. Schematic illustration of the two atmosphere system.

(Fig. 1). 図において $P_{1}, P_{2}$ は大気挂であり, それは水蒸気圧と炭酸ガス分圧との和である. 水蒸気圧はもし水が十分あれば飽和水蒸気圧に等しく, 水が不十分であれば全部を苲発させた 時に示す圧力である，炭酸ガス分圧は，もし液体の海洋が存在すれば海洋によつて規定される 分圧であり [SHIMAZU and URABE (1967)]，海洋が存在しなけ秃ば金星地殼中の炭酸塩との反 応で規定される分圧である。 $T_{1}, T_{2}$ はとのよらな大気における輻射平衡温度である。

気体の平衡分圧は温度の上昇と共にふえるから，高温であれば大気圧は高くなり，低温低圧 の大気の方へ質量輸送が起こり風が吹くそその際に生ずるエネルギー輸送の効果も考慮する. 地球の場合は熱膨張によつて気圧がきまるから，高温ほど低圧になつている，しかし今考劣る ような大気では他の相（海洋または岩石）との平衡関係が大勢を左右する．もし両方の地域に 海洋が存在すれば海流による質量輸送が起こるであろう。しかし金星では昼夜両半球共に海洋 が存在するとは考えられないのでその効果は無視する.

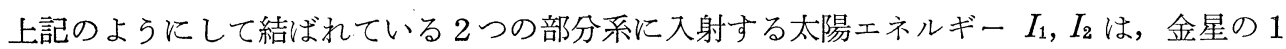
日を周期として単振動をし，その位相は互いに $\pi$ だけずれているものとする。

\section{§3. アルゴリズム}

水と炭酸ガスの質量の時間変化は，たとえば系 1 から系 2 へ輸送される場合について次式で 与えられる。 


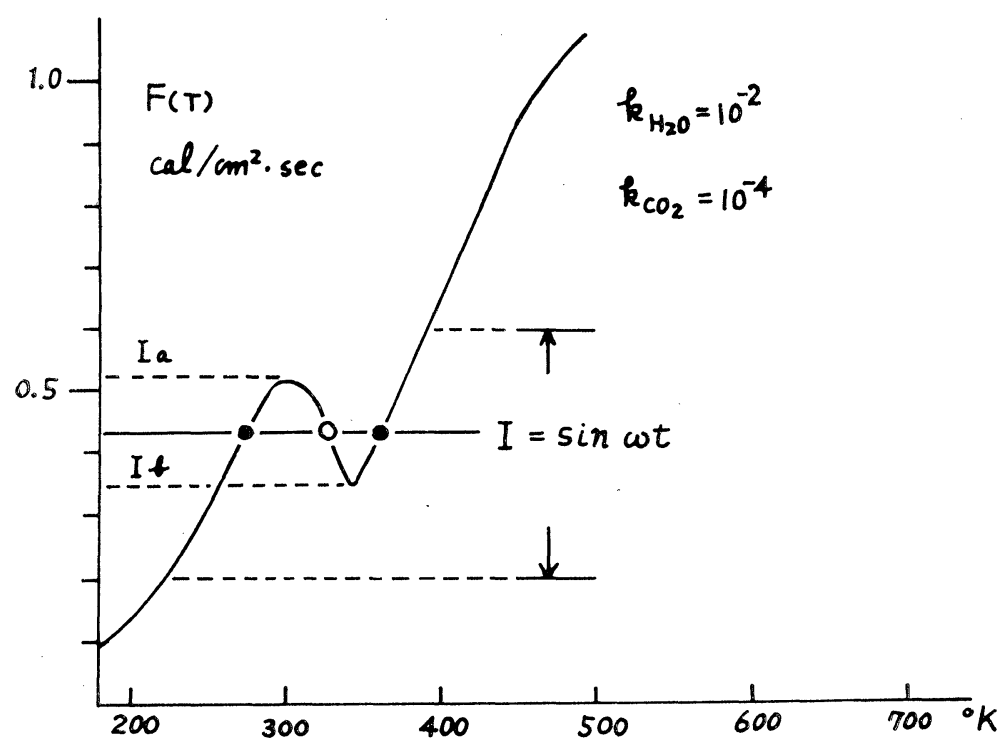

(A)

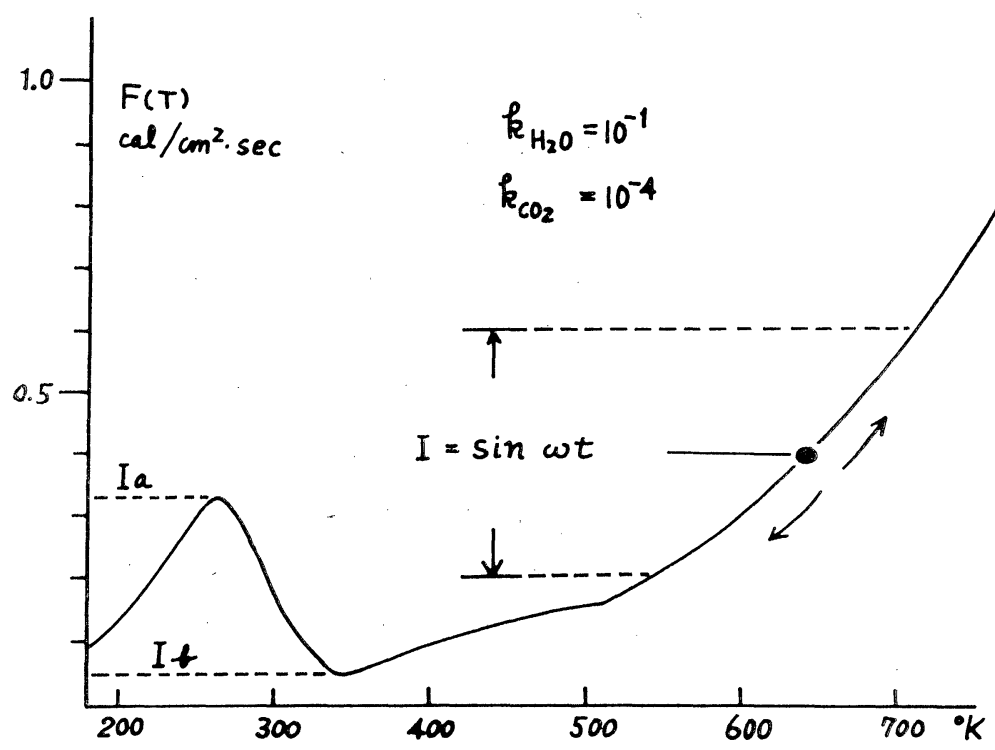

(B)

Fig. 2. Energy flux by infra-red radiation (how to obtain the equilibrium temperature is also schematically shown).

(A) case of $k_{\mathrm{H}_{2} \mathrm{O}}=10^{-2}$

(B) case of $k_{\mathrm{H}_{2} \mathrm{O}}=10^{-1}$ 


$$
\left.\begin{array}{c}
\text { 浦 部 達 夫 } \\
H_{1}^{n+1}=H_{1}^{n}-\left[\alpha \frac{H A_{1}^{n}}{H A_{1}+C A_{1}}\left(P_{1}^{n}-P_{2}^{n}\right)\right] \Delta t \\
H_{2}^{n+1}=H_{2}^{n}+\left[\alpha \frac{H A_{1}^{n}}{H A_{1}^{n}+C A_{1}^{n}}\left(P_{1}^{n}-P_{2}^{n}\right)\right] \Delta t \\
C_{1}^{n+1}=C_{1}^{n}-\left[\alpha \frac{C A_{1}^{n}}{H A_{1}^{n}+C A_{1}^{n}}\left(P_{1}^{n}-P_{2}^{n}\right)\right] \Delta t \\
C_{1}^{n+1}=C_{2}^{n}-\left[\alpha \frac{C A_{1}^{n}}{H A_{1}^{n}+C A_{1}^{n}}\left(P_{1}^{n}-P_{2}^{n}\right)\right] \Delta t
\end{array}\right\}
$$

ここで, $H=$ 水の総量, $H A=$ 大気中の水の質量, $C=$ 炭酸ガスの総量, $C A=$ 大気中の炭 酸ガスの質量, $\alpha=$ 此例定数である. 添字 $n$ は time $=n \times \Delta t$ を示す.

質量輸送に伴つて運ばれる熱量 $Q$ は, たとえば系 1 から系 2 への移動の場合,

$$
Q=T_{1} \times\left(H_{1}^{n+1}-H_{1}^{n}\right) \times C g
$$

となる，ただし $C g$ は大気の比熱である. 系 1 では質量の減少があるので $Q$ を失つても温度 は変化せず，系 2 では質量の増加を考虑すると。

$$
\Delta Q=\left(T_{1}-T_{2}\right) \times\left(H_{1}^{n+1}-H_{1}^{n}\right) \times C g
$$

のエネルギーを受け入れることになり，これが太陽からの入射ェネルギーにつけ加わるのであ る.

水と炭酸ガスとの質量を与えたとき，各温度における輻射エネルギー $F(T)$ を灰色大気の 仮定の下に計算すると，Fig. $2(\mathrm{~A})$ ，(B) のようになる. $F(T)$ の形は水の質量 $H$, 炭酸ガス の質量 $C$, それらの吸収係数 $k_{\mathrm{H}_{2}} \mathrm{O}, k_{C \mathrm{O}_{2}}$, および重力の加速度 $g$ に依存し Fig. 2 (A), (B) は れぞれ， $k_{\mathrm{H}_{2} \mathrm{o}}=10^{-2}, k_{\mathrm{CO}_{2}}=10^{-4}$ 及び $k_{\mathrm{H}_{2} \mathrm{o}}=10^{-1}, k_{\mathrm{CO}_{2}}=10^{-4}$ の場合である.

輻射平衡温度は入射エネルギー $I$ または式 (3) を考慮した実効入射エネルギー $I^{\prime}=I+\Delta Q$ とF $F(T)$ との交点として求められ，Fig. 2 の黑丸がこれに相当する. 白丸は交点ではあつて も不安定なので平衡温度の意味を持たない [SHIMAZU and URABE (1968)]. $I_{a} \leqq I \leqq I_{b}$ に拉 いては 2 つ平衡温度が存在する. どちらの温度が実現されるかは系の履歴による.すなわち 高度から下つてきた場合は高温側の平衡温度をとり, 低温から上つてきた場合は低温側の平衡 温度をとる．従つて， $I_{a} \leqq I_{1}, I_{2} \leqq I_{b}$ のときは， $I_{1}>I_{2}$ なのに $T_{1}<T_{2}$ となる場合もあ る.

具体的な計算手順としては， $T^{n}$ に打ける蒸気压と炭酸ガス分压を用いて $H A^{n}, C A^{n}$ を求 め, 蒸気圧と炭酸ガス分圧の和として $P^{n}$ を計算すればよい. 次に式 (1) を用いて $H^{n+1}$, $C^{n+1}$ を計算し, 同時に $I^{n+1}$ を用いて $T^{n+1}$ を求めるという前進操作を繰返す。 $H^{n+1}, C^{n+1}$ と $I^{n+1}$ を用いて $T^{n+1}$ を出すときに $F(T)$ が必要であるが, $H^{n+1}, C^{n+1}$ が変化する毎に 

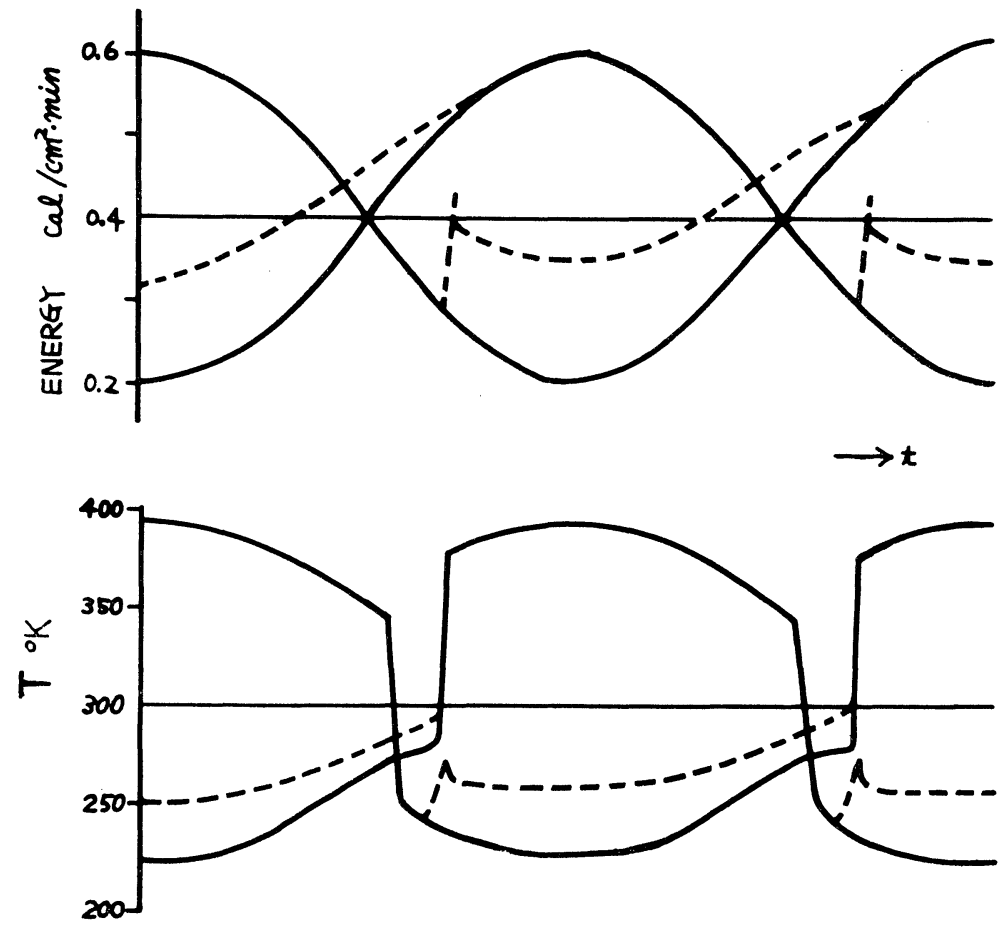

(A)
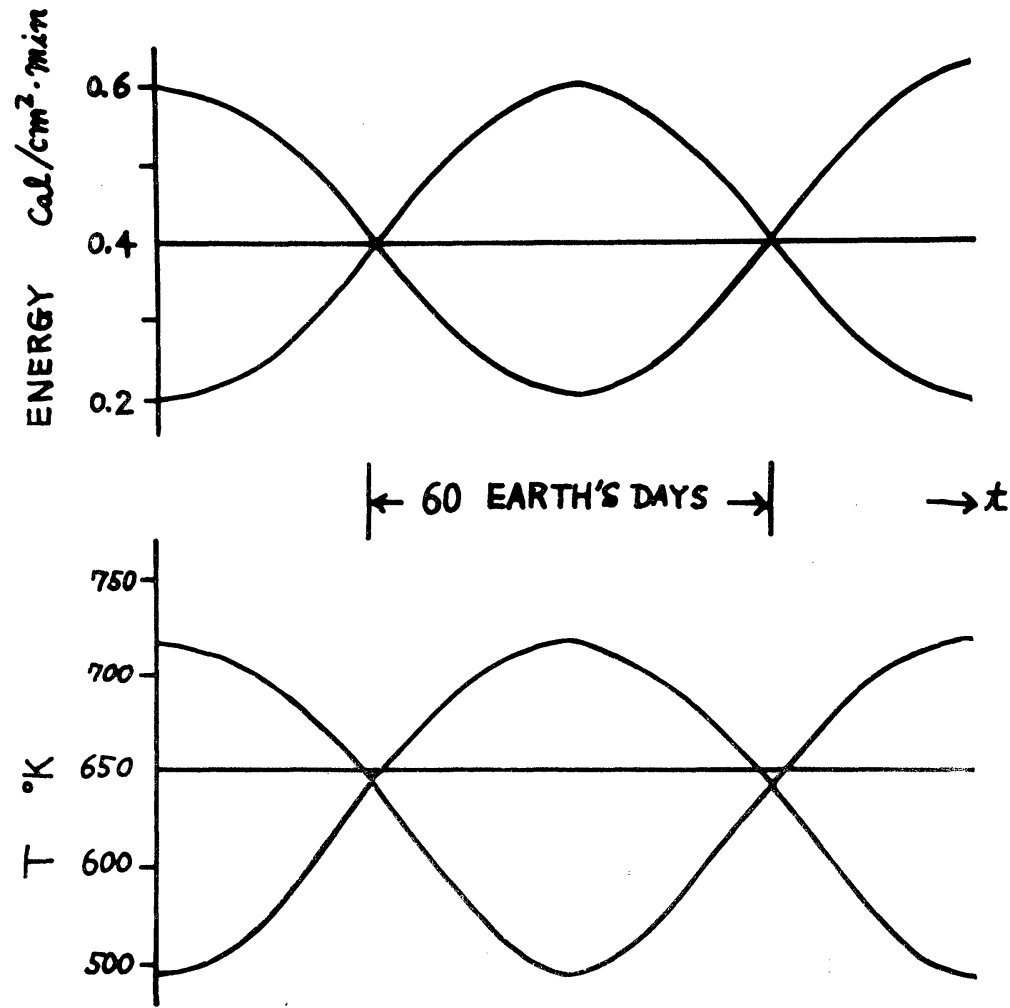

(B)

Fig. 3. Daily variation of cytherean surface temperature.

(A) case of discontinuous jump

(B) case of sinusoidal vasiation 
その関数形を計算し直す必要がある。しかしその手順は計算機の時間制限のために実行不可能 なので, $H^{0}, C^{0}$ つまり初期值として与えた水と炭酸ガスの総量についてだけ $F(T)$ を計算 し，その後のステップにもこの $F(T)$ を用いることにした。

\section{$\S 4$. 結 果}

水の総量 $H=0.292 \times 10^{3} \mathrm{gr} / \mathrm{cm}^{2}$ (地球の場合の 1000 分の 1 ), 炭酸ガスの総量 $C=0.17 \times$ $10^{5} \mathrm{~g} / \mathrm{cm}^{2}$ (17気圧相当でロケット観測で報告されている量と同程度) を初期值として計算した $I$ と $T$ の関係を Fig. $3(\mathrm{~A})$ ，(B) に示す。な括式（1）に拈ける比例定数 $\alpha$ を $0.1 \times 10^{-3}$ $\mathrm{gr} / \mathrm{cm}^{2} \cdot \mathrm{sec} \cdot \mathrm{bar}$ においたが，これは 17 気圧の差があれば金星での 1 日で大気が全部入れか わる程度の大きさであることを意味する. Fig. 3 (A) では $k_{\mathrm{H}_{2} \mathrm{o}}=10^{-2}, k_{\mathrm{CO}_{2}}=10^{-4}$, Fig. 3 (B) では $k_{H_{2} o}=10^{-1}, k_{C O_{2}}=10^{-4}$ と仮定した. 両者は Fig. $2(\mathrm{~A})$, (B) に示した $F(T)$ に それぞれ対応している。

Fig. $3(\mathrm{~A})$ ，(B) の実線は式（3）の $\Delta Q$ ，すなわち風によるエネルギー運搬を無視した場合 であり，破線は $\Delta Q$ を考慮した場合である．Fig. $3(\mathrm{~A})$ のように複雑な温度変化になるか， それとも Fig. 3 (B) のように単純な変化になるかは入射ェネルギーIが Fig. 2 (A), (B) の $F(T)$ の極小值より小さくなるかどうかにかかつている. Fig. $3(\mathrm{~A})$ では，もし十分な水さ えあれば海洋や氷が存在する程度に低温になる。ここでいう十分な水とは，常温での飽和水蒸 気圧 $20 \mathrm{mb}$ 程度以上の量を意味する. $20 \mathrm{mb}$ は金星大気の全圧の $0.1 \%$ に相当する. この值 は, Venera-4 が $0.1 \%$ 以上の水の存在を報告して [AVDUEVSKIY et al. (1968)] 結果の真偽 が問頭となつているまさにその量なのである。

Fig. 3 (B) では両面とも高温なので水も炭酸ガスも大部分大気中に存在し，気圧の差が小さ いので風による熱輸送はあまり大きくはない。

この計算は東京大学大型計算機センターの HITAC $5020 \mathrm{E}$ にった（課題番号 $4001 \mathrm{CB}$ 0077). $F(T)$ について前述のように近似を行つたにもかかわらず，金星の半日分を計算する のに 5 分を要する. その理由は $\Delta t$ を周期の 100 分の 1 程度にとる必要があるからである.

この研究は島津康男氏の指導を受けて行つた。

\section{文献}

AvduevskiY, V.S., M. Y. Marov, and M. K. Rozhdestvenskiy, 1968, The model of the atmosphere of the planet Venus on the results of measurements made by the Soviet automatic interplanetary station Venera 4 . preprint.

Shimazu, Y. and T. Urabe, 1967, Some numerical experiments on the evolution of the terrestrial atmosphere and hydrosphere. Jour. Phys. Earth. 15, $1 \sim 18$.

Shimazu, Y. and T. URABE, 1968, An energetic study of the evolution of the terrestrial and cytherean atmospheres. Icarus 9, 498 506. 